\title{
Digestibilidade e balanços metabólicos da silagem de grãos úmidos de milho para suínos ${ }^{1}$
}

\author{
Digestibility and metabolic balances of high moisture corn for pigs
}

\author{
Adalberto dos Anjos da Silva ${ }^{2}$ Brenda Maria Ferreira Passos Prado Marques ${ }^{3}$ Luciano Hauschild $^{4}$ \\ Gerson Guarez Garcia 5 Paulo Alberto Lovatto ${ }^{6}$
}

RESUMO

Dois experimentos foram realizados com o objetivo de avaliar a digestibilidade e balanços metabólicos da silagem de grãos úmidos de milho para suínos. Foram utilizados 12 suínos machos castrados, irmãos paternos, com peso vivo médio de $47 \mathrm{~kg}$, mantidos em gaiolas metabólicas. O experimento 1 teve como objetivo comparar os balanços metabólicos de animais alimentados com dietas contendo milho seco e silagem de grãos úmidos. $O$ experimento 2 teve por objetivo avaliar a digestibilidade da silagem de grãos úmidos. $O$ delineamento experimental utilizado foi o inteiramente casualizado. Cada experimento teve dois tratamentos com quatro repetições de um animal cada. A substituição dos grãos de milho seco por silagem de grãos úmidos em dietas de suínos não influenciou $(P>0,05)$ os balanços do nitrogênio e da energia. A silagem de grãos úmidos de milho apresentou coeficientes de digestibilidade de $85 \%$ para a proteína bruta, $90 \%$ para a energia bruta e 90\% para matéria seca. A substituição do grão de milho seco por silagem de grãos úmidos de milho na dieta de suínos não afeta os balanços do $N$ e da energia. A silagem de grãos úmidos de milho apresenta teores digestíveis de MS, energia bruta e metabolizável superiores quando comparados aos do grão de milho seco.

Palavras chave: nutrição, nitrogênio, fósforo, energia.

\begin{abstract}
Two experiments were carried out to evaluate metabolic balances and the digestibility of the high moisture corn in pigs. Twelve littermates barrows were used, weighting $47 \mathrm{~kg}$ of initial BW, kept into metabolic cages. Experiment one compared the metabolic balances of animals fed with diets contend dry corn and high moisture. Experiment two evaluated the digestibility of high moisture corn. In experiment one, the design was completely randomized. Each experiment had two treatments, four repetitions of one animal. The substitution of the dry corn for high moisture corn did not influence the balances of either nitrogen or energy. The digestibility coefficients of the high moisture corn were: $85 \%$ to crude protein, $90 \%$ to crude energy and $90 \%$ to dry matter. The substitution of dry corn for high moisture corn in the swine diets does not affect the balances of both nitrogen and energy. The digestibility of the dry matter, crude energy and metabolizavel energy of the high moisture corn were higher than the dry corn ones.
\end{abstract}

Key words: nutrition, nitrogen, phosphorus, energy.

\section{INTRODUÇÃO}

Nas últimas décadas, a suinocultura brasileira tem apresentado períodos cíclicos de

${ }^{1}$ Parte da dissertação de mestrado do primeiro autor.

${ }^{2}$ Médico Veterinário, mestrando do Programa de Pós-graduação em Zootecnia, Universidade Federal de Santa Maria (UFSM), Santa Maria, RS, Brasil. Bolsista do Conselho de Aperfeiçoamento de Pessoal de Ensino Superior.

${ }^{3}$ Graduando em Medicina Veterinária, UFSM, Santa Maria, RS, Brasil. E-mail: brendamarques@ pop.com.br

${ }^{4}$ Zootecnista, mestrando do Programa de Pós-graduação em Zootecnia (UFSM), Santa Maria, RS, Brasil.

${ }^{5}$ Professor Assistente, Departamento de Zootecnia (UFSM), Santa Maria, RS, Brasil.

${ }^{6}$ Professor Adjunto, Orientador, Departamento de Zootecnia, UFSM, CEP 97105-900, Santa Maria, RS, Brasil. E-mail: lovatto@smail.ufsm.br, autor para correspondência. 
rentabilidade devido, principalmente, ao custo elevado dos ingredientes das rações. O milho é, por suas características nutricionais e disponibilidade comercial, o alimento mais utilizado na formulação de rações para suínos, correspondendo a aproximadamente $75 \%$ do volume da ração. No entanto, o processamento do grão de milho seco envolve custos adicionais com transporte, secagem e armazenamento. Além disso, nesse processo, o milho pode servir de substrato para fungos e insetos, alterando sua composição química e seu valor nutricional (LOPES et al., 1990).

Neste contexto, a ensilagem de grãos úmidos de milho pode ser uma alternativa para sua conservação e armazenagem. A ensilagem apresenta vantagens agro-econômicas em relação ao grão de milho seco, como otimização do uso da terra, redução de perdas nos períodos pré e pós-colheita, economia de mão-de-obra e custos de armazenamento (JONES et al., 1974). Além disso, a ensilagem pode garantir a qualidade sanitária do grão (JOBIM et al., 1997) e melhorar a disponibilidade de seus nutrientes (LOPES, 2000).

Para suínos, a silagem de grãos úmidos de milho apresenta maior digestibilidade da energia (LIMA et al., 1999) e do nitrogênio (ASCHE et al., 1986), determinando melhora do ganho de peso e da eficiência alimentar em comparação com as rações contendo milho seco (DUDUK, 1988). A utilização de silagem de grãos úmidos de milho para suínos na fase inicial melhora a conversão alimentar e reduz a prevalência de diarréia em relação ao milho seco (LOPES, 2000). O melhor valor nutricional de dietas contendo silagem se deve às alterações físicas e químicas que ocorrem no endosperma e na superfície dos grânulos de amido durante o processo fermentativo, podendo aumentar a susceptibilidade ao ataque enzimático durante a digestão (LOPES et al., 2002).

As vantagens técnicas e econômicas da silagem de grãos úmidos de milho têm estimulado sua utilização pelos suinocultores. Mas essas vantagens não têm unanimidade na pesquisa. Os resultados de digestibilidade de dietas contendo silagem de grãos úmidos são variáveis, o que sugere estudos com mais detalhamentos sobre o tema. Este trabalho teve, portanto, o objetivo de avaliar a digestibilidade da silagem e balanços metabólicos de dietas contendo grãos úmidos de milho para suínos.

\section{MATERIAL E MÉTODOS}

O experimento foi realizado no Setor de Suinocultura da UFSM, entre fevereiro e março de 2004. Foram utilizados 12 suínos machos castrados, geneticamente homogêneos e irmãos paternos, oriundos de cruzamentos industriais entre as raças Landrace, Large White e Duroc, com $47 \mathrm{~kg}$ de peso vivo médio inicial. Os animais foram alojados em gaiolas metabólicas, semelhantes às descritas por PEKAS (1968), mantidas em ambiente controlado a $22^{\circ} \mathrm{C}$. O milho utilizado para a elaboração da silagem foi uma associação de híbridos comerciais colhidos em fevereiro de 2004 no município de Toropi (RS). A colheita do milho foi realizada mecanicamente, e os grãos triturados em moinho tipo martelo sem a utilização de peneira, sendo em seguida ensilados em silos plásticos.

Foram realizados dois experimentos, um para comparar os balanços metabólicos de animais alimentados com dietas com grãos de milho seco (tratamento controle - T1) e úmido (tratamento - T2), e outro para avaliar a digestibilidade da silagem de grãos úmidos de milho (T1 x tratamento - T3 com substituição volumétrica de $40 \%$ por silagem de grãos úmidos de milho). O delineamento experimental utilizado foi o inteiramente casualizado. Cada tratamento teve quatro repetições, tendo o animal como unidade experimental. No experimento 1, as dietas experimentais $\mathrm{T} 1 \mathrm{e} \mathrm{T} 2$ foram formuladas para atender as exigências nutricionais sugeridas pelo NRC (1998). No experimento 2, a dieta T3 foi composta por uma substituição volumétrica da dieta T1 por $40 \%$ de silagem de grãos úmidos de milho. A composição das dietas experimentais está apresentada na tabela 1 . O período experimental foi de 12 dias (sete de adaptação dos animais às gaiolas e ao alimento; cinco dias de coleta). A quantidade diária de ração foi ajustada de acordo com a estimativa do ganho médio diário, considerando um consumo de 2,6 vezes a mantença estimada em 250 kcal EM kg ${ }^{-0,60}$ (NOBLET et al., 1993). $\mathrm{O}$ alimento foi distribuído em três refeições diárias, às 8,13 e 18 horas e os animais tiveram livre acesso à água.

Foi utilizado o método de coleta total de fezes. O início e o fim da coleta foram determinados pelo aparecimento de fezes marcadas (foi adicionado 1,5\% de $\mathrm{Fe}_{2} \mathrm{O}_{3}$ às dietas). As fezes foram coletadas a cada $12 \mathrm{~h}$, acondicionadas em sacos plásticos e conservadas em congelador $\mathrm{a}-10^{\circ} \mathrm{C}$. No final do experimento, as fezes foram homogeneizadas e amostradas $(0,5 \mathrm{~kg})$, secas em estufa de ventilação forçada $\left(60^{\circ} \mathrm{C}\right.$ durante $\left.72 \mathrm{~h}\right)$ e moídas para análises posteriores. A urina excretada foi drenada para baldes plásticos contendo $25 \mathrm{~mL}$ de $\mathrm{HCl} 6 \mathrm{~N}$. A cada $12 \mathrm{~h}$, após homogeneização, o volume e a massa foram medidos e uma amostra de $5 \%$ do volume foi retirada e conservada sob refrigeração $\left(4^{\circ} \mathrm{C}\right)$. As análises químicas de fezes e urina foram realizadas segundo metodologia 
Tabela 1 - Ingredientes e composição analisada das dietas experimentais, T1 (dieta com milho seco), T2 (dieta com silagem de grãos úmidos de milho) e T3 (substituição volumétrica da dieta T1 por $40 \%$ de silagem de grãos úmidos de milho)

\begin{tabular}{llll}
\hline & \multicolumn{3}{l}{ Dietas experimentais } \\
Ingredientes ${ }^{1}, \%$ & $\mathrm{~T} 1$ & $\mathrm{~T} 2$ & $\mathrm{~T} 3$ \\
\hline Milho & 74,97 & - & 44,98 \\
Silagem de grão úmido de milho & - & 77,30 & 40,00 \\
Farelo de soja & 21,40 & 20,17 & 12,84 \\
Óleo vegetal $_{\text {Premix }}{ }^{2}$ & 0,63 & - & 0,38 \\
Total & 3,00 & 2,53 & 1,80 \\
Composição analisada ${ }^{3}$ & 100,00 & 100,00 & 100,00 \\
Matéria seca, \% & & & \\
Energia bruta, kcal/kg & 85,72 & 71,78 & 78,88 \\
Proteína bruta, \% & 4043 & 4199 & 4180 \\
Fósforo, \% & 16,86 & 16,46 & 14,86 \\
Extrato etéreo, \% & 0,58 & 0,53 & 0,54 \\
Fibra detergente neutro, \% & 6,07 & 6,05 & 5,94 \\
Fibra bruta, \% & 15,66 & 16,59 & 16,08 \\
& 2,27 & 3,79 & 3,21
\end{tabular}

${ }^{1}$ Matéria natural; ${ }^{2}$ Suplemento vitamínico-mineral. Conteúdo por kg de ração: Vit. A, 228.570 UI; Vit. D3, 34.290 UI; Vit. E, 570 mg; Vit. K3, 71 mg; Vit. B1, 29 mg; Vit. B2, 115 mg; Vit. B6, 57 mg; Vit. B12, 570 mcg; Ác. Nicotínico, 715 mg; Ác. Pantotênico, 290 mg; Biotina, 1,43 mg; Ác. Fólico, $17 \mathrm{mg}$; Selênio, $15 \mathrm{mg}$; Colina, $6.860 \mathrm{mg}$; Lisina, $11.430 \mathrm{mg}$; Antioxidante, $17 \mathrm{mg}$; Iodo, $23 \mathrm{mg}$; Cobalto, $13 \mathrm{mg}$; Cobre, $2.500 \mathrm{mg}$; Zinco, $2.200 \mathrm{mg}$; Ferro, $2.000 \mathrm{mg}$; Manganês, $1.100 \mathrm{mg}$; Ca, $220 \mathrm{~g}$; P, $62 \mathrm{~g}, \mathrm{Na}$ 62 g. ${ }^{3}$ Matéria seca

da AOAC (1990). As análises granulométricas da silagem e do milho seco foram realizadas segundo a metodologia descrita por ZANOTTO \& BELLAVER (1996). O pH da silagem foi determinado pelo método utilizado por PHILLIP \& FELLNER (1992). O teor de N não protéico (NNP) foi determinado segundo o método proposto por TOSI(1973).

No experimento 1, os parâmetros avaliados foram a dinâmica (ingestão, excreções fecal e urinária) do $\mathrm{N}$ e energia. Os dados obtidos foram submetidos à análise de variância através do MINITAB (MCKENZIE \& GOLDMAN, 1999). No experimento 2, foram estimados os coeficientes de digestibilidade aparente da matéria seca $\left(\mathrm{CD}_{\mathrm{a}} \mathrm{MS}\right)$, energia bruta $\left(\mathrm{CD}_{\mathrm{a}} \mathrm{EB}\right)$, proteína bruta $\left(\mathrm{CD}_{a} \mathrm{~PB}\right)$, metabolização da energia bruta (CMEB), energia metabolizável aparente $\left(\mathrm{EM}_{\mathrm{a}}\right)$ e os teores digestíveis totais da matéria seca (MSD), proteína (PD) e energia (ED). Estes coeficientes foram determinados segundo a metodologia proposta por MATTERSON et al. (1965).

\section{RESULTADOS E DISCUSSÃO}

A análise da composição química da silagem de grãos úmidos de milho apresentou valores de $68,3 \%$ de matéria seca, $5,32 \%$ de proteína bruta, $3,32 \%$ de extrato etéreo e $2,59 \%$ de fibra bruta. Estes valores foram superiores, com exceção da proteína bruta, aos propostos pela EMBRAPA (1991), que apresenta valores de $62,53 \%$ de MS, 5,31\% de PB; $2,65 \%$ de EE e $1,66 \%$ de FB para a silagem. A composição química da silagem de grãos úmidos de milho pode apresentar variações. Isso se deve a fatores como potencial genético, nível de adubação utilizado (especialmente $\mathrm{N}$ ), fertilidade do solo e condições climáticas (LIMA et al., 1999).

$\mathrm{O}$ pH, a concentração de ácidos orgânicos e o teor de $\mathrm{N}$ amoniacal (\% do $\mathrm{N}$ total) são importantes indicadores qualitativos do processo de ensilagem. $\mathrm{O}$ $\mathrm{pH}$ da silagem utilizada neste experimento foi de 4,01, muito próximo do valor 4 que revela a boa qualidade do produto (McDONALD et al., 1991). A elevação da concentração de ácidos orgânicos, principalmente ácido lático, aumenta a concentração hidrogeniônica do meio, inibindo o crescimento de microorganismos indesejáveis, como as enterobactérias e bactérias do gênero Clostridium, responsáveis pela excessiva proteólise do substrato e produção de toxinas (OHSHIMA \& McDONALD, 1977). No entanto, seu efeito inibidor é dependente da velocidade de declínio do pH (McDONALD et al., 1991).

$\mathrm{O}$ teor do $\mathrm{N}$ amoniacal ou nitrogênio nãoproteico (NNP) da silagem, medido neste experimento, foi de $0,017 \%$ do $\mathrm{N}$ total. O teor de NNP de uma silagem de grãos úmidos de milho de boa qualidade deve ser inferior a $10 \%$ da PB. A quantidade de NNP produzida depende principalmente da quantidade de carboidratos solúveis. Em silagens de grãos úmidos com teores de MS ao redor de $70 \%$, há mais substrato disponível para a produção de ácido láctico, determinando rápido decréscimo do pH e inibição da ação de bactérias (KUNG, 2004).

O diâmetro geométrico médio (DGM) das partículas foi de 2768 e $1784 \mathrm{~mm}$ para a silagem de grãos úmidos e secos de milho, respectivamente. O DGM da silagem observado neste trabalho foi superior ao valor de $1230 \mathrm{~mm}$ recomendado por ZANOTTO \& BELLAVER (1998). A moagem dos grãos aumenta a superfície para ação das enzimas digestivas, melhorando a digestibilidade dos nutrientes (MONTICELLI et al., 1996). Entretanto, alguns estudos de digestibilidade da silagem mostraram valores superiores para os coeficientes de digestibilidade dos nutrientes e energia, comparado ao grão de milho seco, independentemente da granulometria da silagem (TSE, 2004).

$\mathrm{O}$ balanço do $\mathrm{N}$ está apresentado na tabela 2. Nenhum dos parâmetros analisados relativos a 
Tabela 2 - Balanço do N de suínos alimentados com dietas contendo milho seco (T1), e silagem de grãos úmidos de milho (T2)

\begin{tabular}{|c|c|c|c|c|}
\hline \multirow{2}{*}{ Parâmetros } & \multicolumn{2}{|c|}{ Tratamentos } & \multirow{2}{*}{$\mathrm{dpr}^{1}$} & \multirow{2}{*}{$\mathrm{P}^{2}$} \\
\hline & $\mathrm{T} 1$ & $\mathrm{~T} 2$ & & \\
\hline $\mathrm{N}$ ingerido, $\mathrm{g} / \mathrm{dia}$ & 49,44 & 47,18 & 1,75 & 0,120 \\
\hline $\mathrm{N}$ fecal, g/dia & 6,66 & 6,14 & 0,59 & 0,259 \\
\hline Coeficiente de digestibilidade, $\%$ & 85,50 & 86,96 & 1,47 & 0,670 \\
\hline $\mathrm{N}$ urinário, g/dia & 13,92 & 16,86 & 4,55 & 0,396 \\
\hline $\mathrm{N}$ absorvido, g/dia & 42,78 & 41,04 & 2,04 & 0,275 \\
\hline $\mathrm{N}$ retido, g/dia & 28,86 & 24,19 & 3,20 & 0,085 \\
\hline $\mathrm{N}$ retido/absorvido, $\%$ & 67,62 & 59,28 & 9,50 & 0,261 \\
\hline
\end{tabular}

${ }^{1}$ desvio padrão residual; ${ }^{2}$ nível de $5 \%$

dinâmica do $\mathrm{N}$ apresentou diferença significativa $(\mathrm{P}<0,05)$. O coeficiente de digestibilidade do $\mathrm{N}$ em suínos alimentados com silagem pode ser superior em relação àqueles que receberam dietas com milho seco (HOLMES et al., 1973). Resultados semelhantes foram obtidos por (ASCHE et al., 1986), que verificaram maior absorção de $\mathrm{N}$ em rações com silagem, comparada à ração elaborada com milho seco. Isto pode ser explicado pela ação química dos ácidos orgânicos sobre a integridade da matriz protéica dos grãos de milho. Foi observado por LOPES (2000) que a ação microbiana e/ou dos ácidos orgânicos gerados no processo de ensilagem, comprometeu severamente a integridade da matriz protéica, aumentando sua solubilidade.

Os resultados para o $\mathrm{N}$ retido e urinário devem ser analisados tendo como foco a questão metabólica do N. É possível que durante o processo de ensilagem ocorra desaminação e descarboxilação aminoacídica, transformando parte do $\mathrm{N}$ protéico em NNP, pelos diferentes processos fermentativos (OHSHIMA \& McDONALD, 1977). Isso determinaria uma absorção semelhante de $\mathrm{N}$, como a verificada neste experimento, mas reduziria a síntese protéica nos animais alimentados com silagem pela falta de aminoácidos, aumentando a excreção de $\mathrm{N}$ via urinária. Outro fator importante, que interfere no balanço do $\mathrm{N}$ de suínos alimentados com silagem, é a textura do grão a ser ensilado. Dependendo de sua textura, a quantidade de matriz protéica pode ser superior, determinando um efeito significativo sobre a absorção e o metabolismo do N (CANTARELLI, 2003).

O balanço da energia está apresentado na tabela 3. As energias digestível e metabolizável (kcal $\mathrm{kg}^{-1}$ de MS) foram superiores $(\mathrm{P}<0,05)$ em 4,0 e 3,5\% para os animais alimentados com $\mathrm{T} 2$, respectivamente. Resultados semelhantes foram obtidos por TÓFOLI (2004), que verificou uma superioridade de ED e EM nos animais alimentados com silagem em relação aos grãos secos. A maior disponibilidade energética de dietas contendo silagem de grãos úmidos de milho verificada neste experimento pode ser explicada por alterações que ocorrem nas moléculas de amido durante o processo fermentativo (LOPES, 2000). No

Tabela 3 - Consumo, digestibilidade e metabolização da energia de suínos alimentados com dietas contendo milho seco (T1) e silagem de grãos úmidos de milho (T2)

\begin{tabular}{|c|c|c|c|c|}
\hline \multirow{2}{*}{ Parâmetros } & \multicolumn{2}{|c|}{ Tratamentos } & \multirow{2}{*}{$\mathrm{dpr}^{1}$} & \multirow{2}{*}{$\mathrm{P}^{2}$} \\
\hline & $\mathrm{T} 1$ & $\mathrm{~T} 2$ & & \\
\hline Energia ingerida, $\mathrm{kcal} / \mathrm{dia}$ & 7410 & 7523 & 275 & 0,582 \\
\hline Energia digestível, kcal/dia & 6392 & 6512 & 253 & 0,557 \\
\hline Energia digestível, $\mathrm{kcal} / \mathrm{kg}$ de MS & 3487 & 3634 & 36 & 0,001 \\
\hline Energia fecal, g/dia & 1018 & 1011 & 60 & 0,872 \\
\hline Coeficiente de digestibilidade, $\%$ & 86,25 & 86,55 & 0,88 & 0,648 \\
\hline Energia urinária, kcal/dia & 128 & 155 & 42 & 0,397 \\
\hline Energia metabolizável, kcal/dia & 6386 & 6472 & 263 & 0,660 \\
\hline Energia metabolizável, $\mathrm{kcal} / \mathrm{kg}$ de MS & 3360 & 3480 & 23 & 0,000 \\
\hline Coeficiente de metabolizibilidade, $\%$ & 86,18 & 86,02 & 0,57 & 0,699 \\
\hline
\end{tabular}

${ }^{1}$ desvio padrão residual; ${ }^{2}$ nível de $5 \%$

Ciência Rural, v.35, n.4, jul-ago, 2005. 
endosperma dos cereais os grânulos de amido encontram-se envoltos por uma matriz de natureza protéica e, dependendo do método de processamento a que os grãos são submetidos, pode ocorrer o rompimento destas estruturas facilitando a ação enzimática e a digestão de amido.

Os coeficientes de digestibilidade aparente da silagem obtidos, neste experimento, foram de $85 \%$ para a proteína bruta $\left(\mathrm{CD}_{\mathrm{a}} \mathrm{PB}\right), 90 \%$ para a energia bruta $\left(\mathrm{CD}_{\mathrm{a}} \mathrm{EB}\right)$ e $90 \%$ para matéria seca $\left(\mathrm{CD}_{\mathrm{a}} \mathrm{MS}\right)$. Estes resultados são semelhantes aos encontrados por LIMA et al., (1999) que, trabalhando com duas silagens de grãos úmidos de milho granulométricamente diferentes, obtiveram valores de 83 e $86 \%$ para PB, 90 e $91 \%$, para EB e 88 e $89 \%$ para MS. A silagem de grãos úmidos de milho apresenta maiores coeficientes de digestibilidade ileal e total da MS, EB e PB, em comparação à dieta com grãos de milho secos (HOLMES et al., 1973). O coeficiente de metabolizibilidade da energia bruta (CMEB) foi de $83 \%$. Este valor foi $6 \%$ inferior ao obtido por OLIVEIRA et al. (2004). Quando se comparam os $\mathrm{CD}_{\mathrm{a}} \mathrm{EB}, \mathrm{CD}_{\mathrm{a}} \mathrm{PB}$ e $\mathrm{CD}_{\mathrm{a}} \mathrm{MS}$ aos coeficientes de digestibilidade do milho seco publicados pela EMBRAPA (1991), verifica-se que a ensilagem de grãos úmidos de milho melhora a disponibilidade destes nutrientes do milho.

Os teores digestíveis totais da matéria seca (MSD), proteína (PD), energia digestível (ED) e energia metabolizável (EM), estão apresentados na tabela 4. Estes resultados, com exceção da MSD, foram semelhantes aos obtidos por OLIVEIRA et al., (2004) que encontraram valores de $81 \%$ para a MSD, 6,26\% para PD, 3970 kcal kg-1 de ED e $3867 \mathrm{kcal} \mathrm{kg}^{-1}$ de EM, ajustados para $100 \%$ de MS. Resultados superiores foram encontrados por LIMA et al. (1999), que obtiveram valores de 4070 e $3929 \mathrm{kcal} \mathrm{kg}^{-1}$ de MS para as energias, digestível e metabolizável,

Tabela 4 - Matéria seca digestível (MSD), proteína digestível (PD), energia digestível (ED) e energia metabolizável (EM) da silagem (na matéria natural e seca) e do milho na matéria seca

\begin{tabular}{lcccc}
\hline \multirow{2}{*}{ Ingredientes } & \multicolumn{4}{c}{ Teores digestíveis } \\
\cline { 2 - 5 } & MSD,\% & PD,\% & ED, kcal/kg & EM, kcal/kg \\
\hline Silagem $^{1}$ & 61,82 & 4,54 & 2708 & 2629 \\
Silagem $^{2}$ & 90,51 & 6,65 & 3965 & 3849 \\
Milho $^{3}$ & 86,10 & 7,51 & 3849 & 3742
\end{tabular}

${ }^{1}$ Valores analisados: MS, \% - 68,3; PB, \% - 5,32; EE, \% - 3,32; FB, \% - 2,59; ${ }^{2}$ Valores ajustados para $100 \%$ de MS; ${ }^{3}$ EMBRAPA (1991) respectivamente. Os resultados obtidos, quando comparados ao grão de milho seco (EMBRAPA, 1991), foram em média $4 \%$ superiores, com exceção da PD que foi $11 \%$ inferior.

A maior disponibilidade nutricional da silagem em relação aos grãos secos pode ser explicada principalmente pelo seu menor valor de $\mathrm{pH}$. Os ácidos orgânicos produzidos durante o processo fermentativo podem causar rupturas na matriz protéica que recobre os grânulos de amido, bem como na estrutura desses grânulos, favorecendo a digestão e absorção do amido (LOPES, 2000).

\section{CONCLUSÃO}

A substituição do grão de milho seco por silagem de grãos úmidos de milho na dieta de suínos não afeta os balanços do $\mathrm{N}$ e da energia. A silagem de grãos úmidos de milho apresenta teores digestíveis de MS, energia bruta e metabolizável superiores quando comparados aos do grão de milho seco.

\section{REFERÊNCIAS}

AOAC. Official Methods of Analysis. 15.ed. Arlington, VA. : Association of Official Analytical Chemistis, 1990. $1117 \mathrm{p}$.

ASCHE, G.L. et al. Effect of dry, high-moisture and reconstituted normal and high-lysine corn diets and particle size on energy and nitrogen metabolism in growing swine. Journal of Animal Science, v.63, n.1, p.131-138, 1986.

CANTARELLI, V.S. Composição química, vitreosidade e digestibilidade de diferentes híbridos de milho para suínos. 2003. 36f. Dissertação (Mestrado em Zootecnia) Universidade Federal de Lavras.

DUDUK, V. High moisture corn for fattened pigs. Journal of the Faculty Georgikon for Agriculture, v.1, p.71-78, 1988 .

EMPRESA BRASILEIRA DE PESQUISA E AGROPECUÁRIA - EMBRAPA. Tabela de composição química e valores energéticos de alimentos para suínos e aves. 3.ed. Concórdia : EMBRAPA - CNPSA, 1991. 97p.

HOLMES, J.G. et al. Digestion and absorption of dry and high-moisture maize diets in the small and large intestine of the pigs. British Journal of Nutrition, v.30, n.3, p.401401, 1973.

JOBIM, C.C. et al. Presença de microrganismos na silagem de grãos úmidos de milho ensilado com diferentes proporções de sabugo. Pesquisa Agropecuária Brasileira,v.32, n.2, p.201-204, 1997.

JONES, G.M. et al. Organic acid preservation of high moisture corn and other grains and the nutritional value a review. Journal of Animal Science, v.54, n.4, p.499517, 1974.

Ciência Rural, v.35, n.4, jul-ago, 2005. 
KUNG, L. Silage fermentation \& additives. Capturado em 20 jun. 2004. Online. Disponível na Internet http:// www.uwex.edu/ces/crops/uwforage/storage.htm

LIMA, G.J.M.M. et al. Composição química e valor energético de silagem de grãos úmidos de milho para suínos. Concórdia : EMBRAPA, 1999. 2p. (Comunicado Técnico, 40).

LOPES, A.B.R.C. Silagem de grãos úmidos de milho em rações de suínos nas fases inicial, de crescimento e de terminação. 2000. 42f. Dissertação (Mestrado em Zootecnia) - Faculdade de Medicina Veterinária e Zootecnia, Universidade Estadual Paulista, Botucatu.

LOPES, A.B.R.C. et al. Efeito do processo de ensilagem de grãos úmidos de milho nas características do amido. Brazilian Journal of Food Technology, v.5, n.96, p.177-181, 2002.

LOPES, D.C. et al. Efeito do nível de carunchamento do milho sobre a digestibilidade de sua proteína e energia para suínos em crescimento. Revista Brasileira de Zootecnia, v.19, n.3, p.181-185, 1990.

MATTERSON, L.D. et al. The metabolizable energy of feed ingredients for chickens. Stors: Connecticut, the University of Connecticut. Agricultural Experiment Station. 1965. 11p. (Research Report).

McDONALD, P. et al. The biochemistry of silage. 2.ed. Merlow : Chalcombe Publications, 1991. 226p.

McKENZIE, J.; GOLDMAN, R.N. The student edition of Minitab for windows manual: Release 12 . Softcover ed. Addison : Wesley Longman, Belmont, 1999. 592p.

MONTICELLI, C.J. et al. Efeito da granulometria do milho, da área por animal e do sexo sobre o desempenho de suínos em crescimento e terminação. Revista da Sociedade Brasileira de Zootecnia, v.25, n.6, p.1150-1162, 1996

NATIONAL RESEARCH COUNCIL (NRC). Nutrient requirements of swine. 10.ed. Washington : National Academy, 1998. 189p.

NOBLET, J. et al. Metabolic utilization of dietary energy and nutrients for maintenance energy requirements in sows: Basis for a net energy system. British Journal Nutrition, v.70, p.407-419, 1993
OHSHIMA, M.; McDONALD, P. A review of the changes in nitrogenous compounds of herbage during ensilage. Journal Science Food Agriculture, v.29, p.497-505, 1977.

OLIVEIRA, R.P. et al. Valor nutritivo e desempenho de leitões alimentados com rações contendo silagem de grãos úmidos de milho. Revista Brasileira de Zootecnia, v.33, n.1, p.146156, 2004.

OWENS, F.N. et al. The effect of grain source and grain processing on performance of feedlot cattle: a review. Journal of Animal Science, v.75, n.3, p.868-879, 1997.

PEKAS, J.C. Versatible swine laboratory apparatus for physiologic and metabolic studies. Journal of Animal Science, v.27, n.5, p.1303-1309, 1968.

PHILLIP, L.E.; FELLNER, V. Effects of bacterial inoculation of high moisture ear corn on its aerobic stability, digestion and utilization for growth by beef steers. Journal of Animal Science, v.70, p.3178-3187, 1992.

TÓFOLI, C.A. de. Silagem de grãos úmidos de milho com diferentes teores de óleo sobre o desempenho e digestibilidade em leitões na fase de creche. 2004. 54f. Dissertação (Mestrado em Zootecnia) - Faculdade de Medicina Veterinária e Zootecnia, Universidade Estadual Paulista, Botucatu.

TOSI, H. Ensilagem de gramíneas tropicais sob diferentes tratamentos. 1973. 107f. Tese (doutorado em agronomia) - FCMBB, Universidade Estadual Paulista.

TSE, M.L.P. Valor nutricional da silagem de grãos úmidos de milho com diferentes graus de moagem para leitões na fase de creche. 2004. 54f. Dissertação (Mestrado em Zootecnia) - Faculdade de Medicina Veterinária e Zootecnia, Universidade Estadual Paulista, Botucatu.

ZANOTTO, D.L. et al. Efeito da granulometria do milho sobre a digestibilidade das dietas para suínos em crescimento e terminação. Concórdia : EMBRAPA, 1998. p.1-2 (Boletim Técnico, 223).

ZANOTTO, D.L.; BELLAVER, C. Método de determinação da granulometria de ingredientes para o uso em rações de suínos e aves. Concórdia : EMBRAPA, 1996. p.1-5 (Boletim Técnico, 215). 